\title{
Los ojos de Renata. Anécdota de una paciente superviviente
}

\section{Renata's eyes. A survival patient anecdote \\ Os olhos de Renata. Anedota duma paciente sobrevivente}

\begin{abstract}
María Jesús Martín González
Diplomada Universitaria en Enfermería.

Cómo citar este artículo en edición digital: Martín González, M J. (2017). Los ojos de Renata. Anécdota de una paciente superviviente. Cultura de los Cuidados (Edición digital), 21(48). Recuperado de < http://dx.doi.org/10.14198/cuid.2017.48.08>

Correspondencia: Avda. Victoria Kent n 12, Bloque 1, 2º- A. 29740 Torre del Mar, Málaga

Correo electrónico: torredelmar2@hotmail.com

Recibido: 04/01//2017; Aceptado: 10/05/2017
\end{abstract}

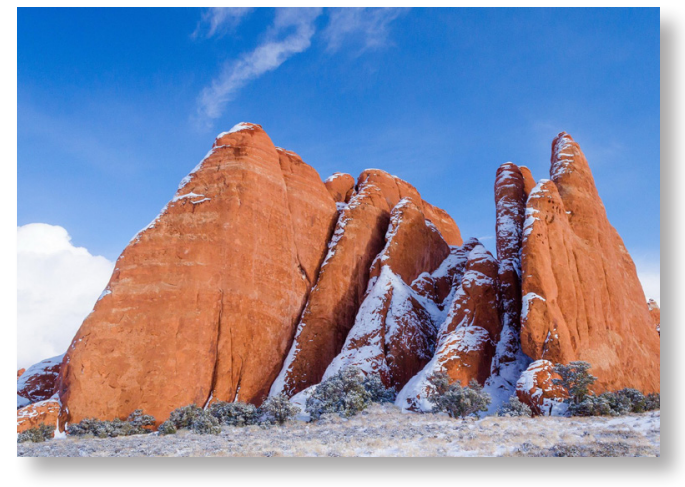

ABSTRACT

Renata had been doubly mastectomized. Surgical wounds had scarred, no longer had the stitches, however, the scars still had that typical pink color of the wounds that have only recently closed. That color "vulnerable-pink". Three were her attempts wto leave, three the feints of leaving and on all three occasions they saved her life that afternoon, in an interval of two or three hours. The absence of breasts in Renata, and her alopecia secondary to chemotherapy and her recent tattoos caused by burns of the defibrillator paddles, right there, in the place where those roses wounds were, gave Renata a bewildering androgynous look, grotesque. Could we ever tell her that she had been about to leave ... ... three ... times? Could we ever tell her with some laughs how head- strong she was, how stubborn?

Key words: Phenomenology, Breast cancer, Self-image, ICU, Survival.

\section{RESUMEN}

Renata había sido doblemente mastectomizada. Las heridas quirúrgicas habían cicatrizado, ya no tenía los puntos de sutura, sin embargo, las cicatrices aún tenían ese color rosáceo típico de las heridas que llevan poco tiempo cerradas. Ese color "rosa vulnerable". Tres veces fueron los intentos de querer marcharse, tres los amagos de partida $y$ en las tres ocasiones le salvaron la vida aquella misma tarde, en un intervalo de dos o tres horas. La ausencia de pechos en Renata, así como su alopecia secundaria a la quimioterapia y los recientes tatuajes por causa de las quemaduras de las palas del desfibrilador, justo en el lugar donde se encontraban aquellas heridas rosas, daban a Renata un aspecto andrógino desconcertante, grotesco. ¿Podríamos contarle alguna vez que había estado a punto de ... irse..., tres..., veces? ¿Podríamos decirle alguna vez con algunas risas que era una mujer muy terca y obstinada?

Palabras clave: Fenomenología, Cáncer de mama, Autoimagen, UCI, Supervivencia. 


\section{RESUMO}

Renata tinha sido mastectomizada duplamente. As feridas cirúrgicas tinhan curado, já não tinha os pontos de sutura, no entanto, as cicatrizes ainda tinhan aquela cor-de-rosa típico das feridas que só recentemente fechadas. Que a cor “rosa vulnerável”. Três foram as tentantivas dela querendo deixar, três as fintas de sair embora e em todas as três ocasiões salvaram a sua vida, essa mesma tarde, em um intervalo de duas ou três horas. A ausência de seios en Renata, e sua alopecia secundária à quimioterapia, e tatuagens recentes causado por queimaduras as pás do desfibrilador, bem no lugar onde essas feridas rosas eram, deu Renata uma aparência andrógina grotescamente desconcertante. Poderíamos alguma vez dizer que ela estava prestes a sair ... ... três ... vezes? Poderíamos alguma vez dizer com algumas risadas que era uma mulher muito teimosa?

Palabras chave: Fenomenologia, Cancro de mama, Auto-imagem, UCI, Sobrevivência.

Tres reanimaciones cardiopulmonares en la misma tarde. Así fue como se le dio la bienvenida a Renata en nuestra unidad. Renata es un nombre ficticio para una persona real, que fue real, o que aún lo sigue siendo; lo ignoro.

No participé en ninguna de las tres reanimaciones. Ni tan solo me acerqué. No me atreví. Estaba muy "verde" todavía, tenía miedo. No sabría qué hacer, cómo moverme ni dónde ponerme. Me sentía bloqueada, y por lo tanto, lo estaba, totalmente paralizada en mi interior, en la distancia, y, en mi exterior, disimulaba ocupándome de mis tareas con otro paciente, que estaba a mi cargo, y que afortunadamente no sufría ningún tipo de emergencia. Desde luego estaba aliviada de saber que las otras veteranas enfermeras de la unidad acudían raudas y eficaces a cada una de las paradas de Renata. Tres veces fueron los intentos de querer marcharse, tres los amagos de partida y en las tres ocasiones le salvaron la vida aquella misma tarde, en un intervalo de dos o tres horas.

Renata había sido doblemente mastectomizada. Las heridas quirúrgicas habían cicatrizado, ya no tenía los puntos de sutura, sin embargo, las cicatrices aún tenían ese color rosáceo típico de las heridas que llevan poco tiempo cerradas. Ese color "rosa vulnerable". Cicatrices. Qué fea palabra, palabra tabú, palabra que hay que evitar si estás cerca de un paciente oyente; eso lo aprendí años más tarde, cuando cambié de unidad, cuando pasé a quirófano y me di cuenta de lo terrible que podía resultar oír hablar de cicatrices, muerte, sangre y otros temas tarantinescos delante de un paciente a punto de recibir una intervención quirúrgica y al que aún no se le había aplicado la anestesia general o sedación. Ni cicatrices, ni política ni religión, sencilla norma de cortesía.

La palabra muerte no combina bien con la decoración de la sala de operaciones, ni siquiera para la expresión "morirse de risa"; en ese caso, será mejor reír de una manera más discreta.

La ausencia de pechos en Renata, así como su alopecia secundaria a la quimioterapia y los recientes tatuajes por causa de las quemaduras de las palas del desfibrilador, justo en el lugar donde se encontraban aquellas heridas rosas, daban a Renata un aspecto andrógino desconcertante, grotesco. Era como estar ante un personaje salido de Mad Max, desplomado tras una furia en la carretera infernal de la vida. Ahí estaba Renata, sedada, intubada, quemada y sin conciencia ni consciencia de su heroica 
supervivencia.

¿Podríamos contarle alguna vez que había estado a punto de ...irse..., tres..., veces? ¿Podríamos decirle alguna vez con algunas risas que era una mujer muy teimosa, muy obstinada?

Aún no me había adaptado completamente a aquella unidad de cuidados intensivos, bueno..., ni a aquel país, tan cercano pero tan diferente. Ya empezaba a entender mejor el portugués, $y$, a fuerza de escribir incidencias, también mejoraba mi redacción.

En los cambios de turno había media hora en común entre el equipo profesional entrante y el saliente. Durante ese tiempo se leían en voz alta las incidencias registradas durante ese turno por cada paciente ingresado.

[Cama 1. Renata. Paciente consciente, ligeramente sedada. Conectada a ventilación mecánica, con respiración espontánea. Catéter venoso central en subclavia derecha, catéter arterial en radial izquierda. Sonda nasogástrica con alimentación enteral. Sonda vesical. Orina clara. Edemas en miembros superiores e inferiores. Se realizan cambios posturales cada dos horas. Para mañana previsto posible destete ventilatorio...]

Renata tenía una mirada un tanto exoftálmica. Parecía querer decirlo todo con los ojos. Pero, ¿qué tenía que decir? Fuera lo que fuese, sería triste. Su mirada, sus ojos, no eran humanos. Cuando estamos al límite de la supervivencia nos deshumanizamos, nos quedamos en nuestra versión animal únicamente, y miramos con esos ojos con los que miran los animales a través del cristal del zoo.

La frustración debe ser enorme; no poder moverse, ni hablar, ni siquiera poder respirar por uno mismo y tener que ser ventilado por una máquina. Pero una máquina no está viva, una máquina no tiene mérito. El mérito está en el valor de soportar, en la valentía de querer seguir, el espíritu de la supervivencia, el deseo de vivir y para ello aprovechar hasta la más insípida de las moléculas de oxígeno inhalada a través de un tubo de plástico.

Pasaron unos meses. Renata ya pudo desprenderse de la máquina y respirar por sí misma, aunque con dificultad. Estaba lúcida, perfectamente consciente de su situación y de su lucha. Aún no podía levantarse, de hecho, apenas podía moverse. Recibía cambios posturales cada dos horas.

Los cuidados a los pacientes en aquella unidad eran excelentes. Nunca vi producirse ninguna escara en ningún paciente. La higiene era cuidadosa, se aplicaban masajes e hidratación, y cambios posturales muy frecuentes fuera cual fuera la situación del paciente. Durante los dos años que trabajé en aquella Uci, ningún paciente desarrolló úlceras por presión. Si alguno la tenía, era porque venía de otro lugar con ella, y durante su estancia en nuestro servicio, se le resolvía completamente en poco tiempo. Se trataba de un lugar de trabajo con mucha disciplina y con protocolos y técnicas de actuación muy avanzadas. No había lugar para la desidia, la pereza ni la desorganización.

La cama electrónica de Renata permitía ponerla en una posición muy similar a la de sentado. Debido al tratamiento, seguía sin un solo pelo en todo su cuerpo. Su blanca piel y su redondez le daba un aspecto como de mujer luna, una luna pálida de agosto callada, enmudecida por la traqueostomía que hubo que practicarle por su intubación orotraqueal prolongada. Sus ojos saltones miraban sin ver. Se dirigían hacia el vacío, hacia la nada, 
mirando hacia adentro quizá, sus recuerdos o sus anhelos.

No sonreía, seguramente no tenía motivos para ello. Tampoco lloraba, probablemente había superado los límites de la desesperación, se había resignado a la cautividad de su cuerpo débil e inmóvil. Recibía la fisioterapia de cada día con la misma docilidad de la madera de las marionetas.

¿En qué cofre enterrado se encontraban los sentimientos de Renata? ¿Se los habían llevado en algún bote para anatomía patológica por error?

La tarde estaba lluviosa. En el centro comercial se estaba a salvo; calidez, música suave y aroma a inciensos. Pasé junto a la tienda de cosméticos y me acordé de Renata. Pensé que a una piel tan clara le quedaría muy bien un carmín de labios rojo. Como una frambuesa que se cae en la nieve. Haría meses que Renata no se veía reflejada en un espejo. Su narciso interior debía encontrarse mustio. ¿Por qué no regarlo y abonarlo un poco? De repente me dio un ataque de escenógrafa teatral y me llevé de aquella tienda un pintalabios rojo pasión y un lápiz de ojos negro azabache para Renata, y con ello me presenté a la mañana siguiente junto a su cama.

Después de asearla y administrarle su medicación, y estando ya incorporada en su cama, le mostré los cosméticos y le pregunté si quizá le apetecía que le diera un poco de color. Se lo pregunté con miedo, no sabía cómo reaccionaría, ¿y si creía que yo era una estúpida aburrida que la veía horrenda y pretendía jugar a las maquilladoras de cine con ella para divertirme un rato? Si respondía que no, desde luego era totalmente respetable. Quería que se diese cuenta de que me importaba como ser humano y no solo como paciente, objeto de mi trabajo; quería darle color a su vida con una barra de labios. Aceptó. Así que me senté a su lado y me dispuse a ello. Delineé el contorno de sus abultados ojos, que me parecieron aún más esféricos a medida que los rodeaba. Pasé el carmín por sus labios, que eran gorditos como gajos de mandarina, $y$, tal como hacían las mujeres antiguas, utilicé el mismo carmín para frotar un poco suavemente con los dedos sobre sus mejillas, a modo de colorete improvisado. Renata me miraba. No gesticulaba, para dejarme hacer mi trabajo, como una diva se deja acicalar, nerviosa a punto de debutar en su estreno. Pero yo notaba cómo sus ojos me sonreían. Estaban brillosos. Cuando acabé me di cuenta de que estábamos rodeadas. Teníamos un gran público de enfermeras e intensivistas contemplando la acción; estaban expectantes.

No pude creer cuando Renata, mediante gestos, me pidió que quería verse en un espejo. Quería mirarse. ¿Y si no le gustaba mi "obra"? Podría verse ridícula, podría romper a llorar ante la evidencia de su enfermedad reflejada.

Alguien trajo un espejito y se lo acomodé para que Renata pudiera observar su imagen. Todos a su alrededor pudimos verla esbozar una sonrisa que rápidamente creció hasta convertirse en una carcajada muda perfectamente dibujada en su cara de luna llena. Sus ojos se empaparon de lágrimas, en parte por la hilaridad de la situación, en parte por la explosión emocional de los sentimientos reprimidos.

Creo que se alegró mucho de reencontrarse consigo misma tras tanto tiempo.

Creo que se alegró de verse rodeada de personas pendientes tanto de ella como de su momentánea felicidad y aquello daba un poco más de sentido a su dura lucha por la vida. 